\title{
Architecture of Light of the Orthodox Temple
}

\begin{abstract}
Main tendencies, appropriateness and features of the embodiment of the architectural and theological essence of the light are defined in architecturally spatial organization of the Orthodox Church; the value of the natural and artificial light is set in forming of symbolic structure of sacral space and architectonics of the church building.
\end{abstract}

Keywords: the Orthodox Church, sacral space, the light, architectonics, functions of the light, a system of illumination, principles of illumination

\section{Introduction. The problem raising}

As the experience of new-built churches testifies, a process of re-conceiving of national traditions and searches of combination of modern constructions and building technologies last with the traditional architectonic forms of the church building in modern church architecture of Ukraine. Some architects go by borrowing forms of the Old Russian church architecture, other consider it's better to inherit the best traditions of wooden and stone churches of the Ukrainian baroque or realize the ideas of church architecture of the beginning of $X X$. In the east areas the volume-spatial composition of the Russian "synod-empire" of the church style is renovated as the "national sign of church architecture" and interpreted as the new "Ukrainian Renaissance" [1].

In the most projects retreats are quite often traced from the theological requirements for the spatial temple organization, if not to take into account the direct reiteration of historical standards, attempts of free interpretation are noticed by the builders of church canon. Such innovations quite often bring unusual architectonic forms and methods of the spatial organization in architecture of the Orthodox Church.

A symbolism of the light, as a basis of the traditional mode of the church, is used not in a full degree by architects in creative searches of the church architecture appearance. Purposeful appeal of the theory and practice of the modern church architecture to the historical inheritance of the church building and light environment organization is necessary in connection with principle orthodoxy of the East Church and traditional character of its architecture and testifies the necessity to attract the formed principles by ages and facilities of the temple building to problem solving of the modern church architecture.

\section{Basic material statement}

Sacral architecture unlike all other objects of the architecture is characterized with maintenance and structure, which do not get description exceptionally in rational concepts, but carry symbolic sign maintenance, marked with the mystic character and called to incarnate and express holiness, sacred ones - the greatest spiritual values in a traditional form [2]. Exactly in such aspect it's necessary to examine essence and value of the light in space of the Orthodox Church.

In religion and spiritual life of believing people the light is an important and meaningful symbol of combination in their imagination of the celestial and earthly worlds. Through this it occupies a central place among religious characters which are used in the Sainted Letter. From the first book of Old Testament, where the fact of creation of the light by God is specified: "And God said: "Let it be light!"(Genesis 1.3-4), to the last New Testament, where it's said: "A city needs neither a sun nor a moon, they could light it, because God's glory lighted it up..." (App. 21.23), we observe the presence of the light, a fight of the light and darkness [3].

Consequently, from the point of theology the light is God's creation and gift for people; symbolic appearance, dedicated to the advent of God in the real world; sowing of divine energy, which has a reinforcement in the phenomenon of "Favor's light" and represented in a sacral art as a "sowing" round the image of Jesus Christ, sowing of sainted nimbuses. In architecture of the orthodox temple light, except the necessary utilitarian tasks, it concludes and organizes, incarnates and expresses, specifies and symbolizes, because it is the icon of God's energies, all God's posing, eternal attribute of Divine Liturgy. The real light does not contain a final value, its basic setting - symbolically to tell us about Jesus Christ.

In traditional architecture the concept of the divine light altered in concrete perception: a concept "light", "spiritual light", is translated from the books of Bible and works of Authors of the East Church into a language of archi- 
tectural forms and architectonic phenomena in main space forch bullding. Such light emerges from the height of domes (calotte), the light of bright windows, oriented in a celestial height, the light of icon lamps and candles, brilliance of gold background of mosaics, brilliance of silver and gilt of icons, icon-range, church things and others. As an external display of the light is its interaction with numerous elements of internal structure of the temple on a physical level. The light in unity with them creates light-symbolic structure of the church building; its significance and symbolism are literally "intertwined" into spatial structure of the church building. This conclusion is based on the analysis of literary sources, works of theologians, numerous visual and experimental researches of natural illumination of the traditional church building, which served as a foundation for creation of a vivid model of the light church environment - peculiar archetype in organization of church illumination of the east ceremony, which are an evaluation criterion of their architecturally spatial organization [4].

In co-operating with the material frame of the church building and in a considerable measure, determining a position and sizes of separate tectonic elements of the temple (domes, windows of apse etc.), the light juts out as a forming element of architectural structure of the temple. Daylight which gets into the basic space of the temple through windows, together with the light of candles and icon lamps designs light-shady correlations on internal surfaces of the building. Reflected light from icons, frescos, mosaics gives a gleam - radiations of God's glory, which are the most substantial display of spiritual connection of a human-being with God in orthodox temples [5].

On all stages of the temple building development in Ukraine appropriateness of the organization of the light church environment is traced in a close connection with its architectonics. The light was always necessary, substantial, proof recurrent and summarizing element of the whole mode in the orthodox temples. Appropriateness of the organization of the light church environment expresses a progress of systems of illumination, limits of their constancy trend, and consequently principles of their organization.

A principle of the topside light prevailing in church space is the most important, after which the most light streams must enter internal space of the temple through light cuts from its topside tiers, as it was strengthened from beginnings in tradition of the orthodox church.

A religious theological platform of this principle is the symbolism of topside space of the temple and elements of its volume-spatial structure, above all vaults and dome. Domes and vaults are symbols of unearthly Sky. Topside temple space together with vaults and domes is a place of transition of earthly reality into celestial, a step from the state of matter into the state of spirit, visible into invisible.

Circular character of receipt of the natural light in space of the sacred object from the space height under domes, high brightness of light streams, contrast illumination, light mist around vertical axis in light drum space create a visual effect of "isolation" of the dome from the temple corps, getting up and down. This phenomenon is extraordinarily effective from the point of temple architectonics and psychology of

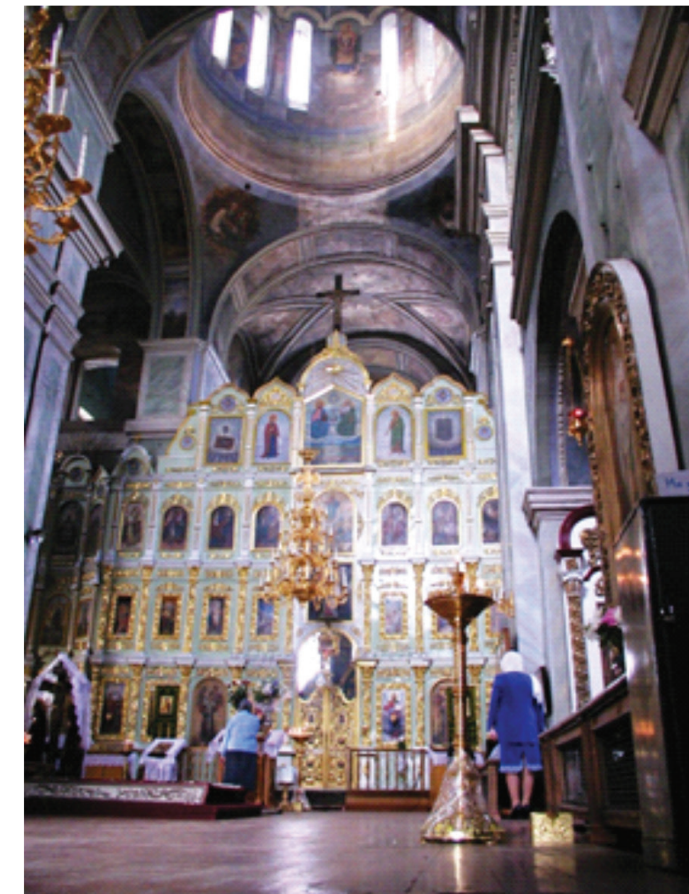

ill. 1. Dominance top light in the space of the church. Trin-

its internal space perception. The connection of symbolism of architectonic forms of the sacred object with the light symbolism makes a mechanism of evolution of architectura forms and temple architectural appearance removable: growth of a central part of the church building upwards provides the character of the pyramidal form.

According to a principle of the topside light prevailing in church space the intensity of light streams and brightness of internal surfaces of the temple must grow bottom-up.

Windows placing and their amount in latera walls, on walls of the light drum of the dome and other parts of the temple, it is needed to group and place thus to provide an indicated character of distributing of light streams from the sun and sky.

Other important principle - a principle of the hierarchical distributing of the light in the basic volume of the church represents the necessity of the uneven distributing of the light for sacred object space - their maximal concentration in the temple center with gradual and sometimes sharp diminishing of the intensity of light streams from a center to periphery of the church building.

Hierarchical symbolism of spaces of the basic church volume increases by the different concentration of daylight streams. The maxima concentration of the natural light and the greatest closeness of light streams on a horizonta plane must be marked, as a rule, in the tem-

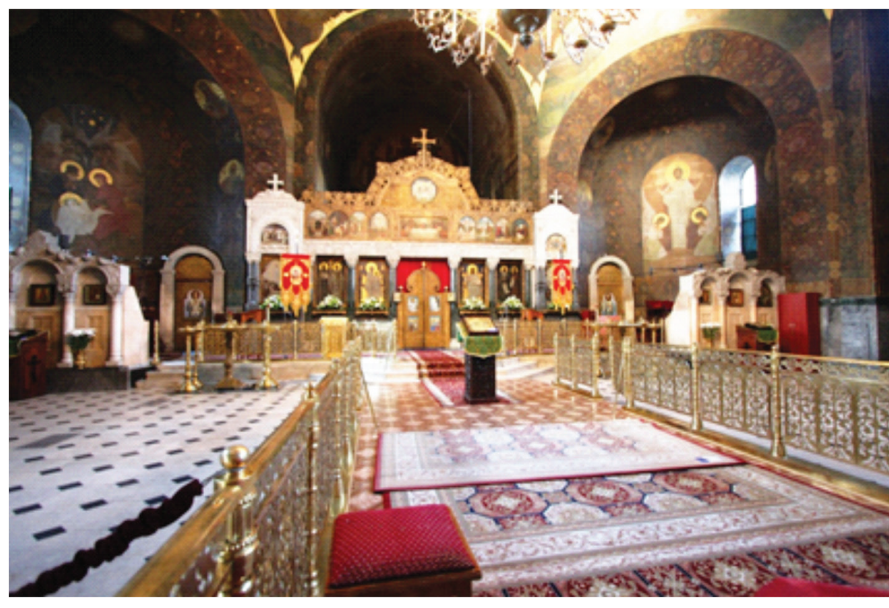

III. 2. Most illuminated center churc
Church of the Kyiv-Pechersk Lavra

ple center, under a central dome. In the case of removal from a center to the external temple walls, luminosity must gradua center to the external temple walls, luminosity must gradu-
ally go down on a horizontal plane, to minimal luminosity unally go down on a horizontal plane, to minimal luminosity unalso changes after a hierarchical order, due to symbolism of also changes after a hierarchical order, due to symbolism of spaces: low luminosity of internal surfaces of external temple walls in its ground tiers is gradually increased to the topside tiers of the sacred object and reaches its maximum on the suraces of the dome light drum.

A system of space illumination of the sacred object, oriented to the theological paradigm of organization of the church light environment, owns universality, so as provides natural perception of space and elements of tectonic temple structure and decoration of its internal surfaces. The diffused lighting as a combination of direct and reflected light is created in large church space. When the reflected light dominates in it shadows do not have clear borders that "muffle" architectonic activity of the forms and plastic arts of their surfaces. Illumination with the direct light is perceived as sharp and ac tive due to more clear shadows and contrast. A combination

III. 3. Natural and artificial light create sacred space of the church. Cyril
Church in Kiev Lavra

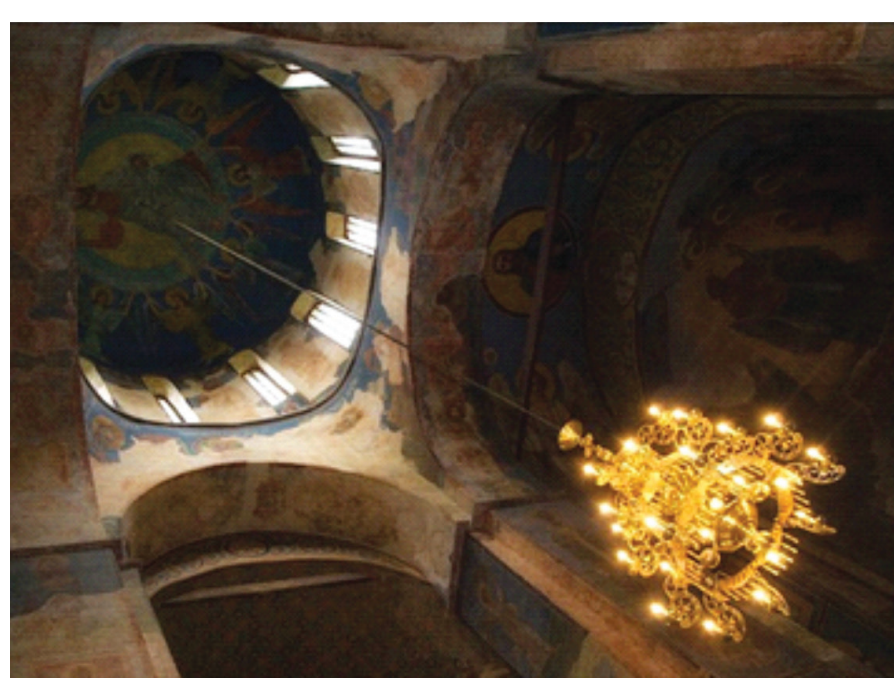

of the direct and reflected light creates soft light-shadow, provides expressive forms and volume details.

A principle of the minimal light sufficiency in the basic church volume sets intensity of light streams, which fill the temple space and levels of luminosity of its surfaces. Redundant glazing is not intrinsic in a plane of walls for the architecture of the traditiona orthodox temple. Arranging of light cuts makes sense only then, when it is necessary to admit the light to the light sacred object, only according to a principle of hierarchical illumination and a principle of prevailing of the topside light. In this case the symbolism of sacral space will be realized on a contrast with a shade, which dominates on periphery of the church building.

Intensity of the natural daylight, which is regulated with an amount, sizes and placing in space of temple windows, taking into accoun the permanent being of the artificial light in Liturgy's time, must not be considerable. For the criterion of luminosity of the horizonta plane it follows to define luminosity necessary for reading of religious texts. Systems of topside and combined (topside with lateral) natural illumination, through the high light activity of windows, always provide necessary levels of utilitarian illumination on the horizontal plane in a central part of the temple. Light-creating, luminiferous and light-reflecting elements of the spatial mode of the church building make a complex of receptions and facilities of the light church environment organization. Constancy of existent facilities of the light church environment organization which are in all types of the orthodox church in Ukraine and reached our days, is explained by sacral symbolism, theological and liturgical essence, which are the most substantia ones, but not aesthetical quality of the architectonic form, lamp or article of divine service in the Christian temple of the east ceremony. For example, a sign-symbol of the God's being in the temple space is a dome - rich in content and architectural center of the sacred object. The dome in the Ukrainian church can change a form and construction, sizes and materials, a size of the light drum, but its space and light are unchangeable, that dominate in it, plying a symbolically mystic, form-generating role. Due to domes, which rise above the corps of the sacred object a principle of the topside light prevailing is realized in its internal space. The light activity of the dome is an intensity of light streams and levels of luminosity, which they create on vertical surfaces and horizontal plane under 
the dome, on the whole it depends on the windows height in the light drum of the dome and their amount.

Even illumination of vaults and domes can decrease their expressiveness and feeling of the space depth. Those forms can be associated with the sky, if the brightness of surfaces of vaults and domes grows from a basis to the top. It's impossible to reach it only with facilities of the natural light, the additional illuminating is to be needed from below by sources of the artificial light.

The hierarchy of symbolism of the basic temple volume is increased with different intensity of light streams of the natural light. The greatest concentration of the light in a center of the sacred object, in space under a dome, especially it underlines sacral meaningfulness of the temple center and the composition value of the vertical axis in space of the dome light drum. Light prevailing in the temple topside spaces, illumination hierarchy of internal space of the sacred objects is complemented with the artificial light. There is a many-tiered candlestick of the censer in the temple center on the vertical axis, alongside smaller candlesticks - the poly-censers. Many candlesticks in temple space, due to the low level of the natural illumination in ground space of the church building are compensated with a system of the artificial light. Sources of the artificial light (not electric), providing divine service functions, organically complement natural illumination in architectonic and utilitarian aspects.

Basic facilities of the natural light organization are windows in church space: in the light drum of the dome, windows in the walls of the apse, windows in walls, which rail in central temple space. They usually have small sizes in comparing to the wall plane, vertical. Sometimes their sizes are increased, but never so that to prevail in walls and temple space. From lightning technology it's known, that at the isometric plane of windows their form substantially does not influence on luminosity in this point of apartment, a position of the window in relation to that point is more important. Those of them, which are lifted up, are oriented in zenith area of the sky and give more luminosity on horizontal and vertical internal surfaces of the temple [6].

Vertical light cuts on the whole height of the nef, which are often used in modern orthodox temples, conflict with theological symbolism of the wall, which is examined as a guarded from the external world in the Christian temple of east ceremony, and a stained-glass window on the whole height of the wall can transform the self-contained space of the church, into the external part. In total, small windows underline a size, sometimes grandeur of the internal temple space and the monumental building. However in the case of small windows in the temple space there is always a very high light-shady contrast between surfaces of the window and wall. This problem was settled by windows placing in two tiers in topside parts of the walls that created a gradual transition from the poor lighted bottom to the light drum. In conditions of the diffuse sky, which prevails in the light climate of Ukraine, there is also a high contrast between the bright plane of the window and small brightness of the walls. Its diminishing was got by arranging round the window of wide slopes, beneath to the window plane, the brightness of which was somehow low than brightness of the window.

\section{Research results}

There is a few levels of the light environment organization, defined in traditional architectonically spatial structure of the East church: sign-symbolic and vividly symbolic in which symbolism of the light (interchangeable with symbolism of light sources, luminiferous and light-reflecting elements of the church building), providing its sacral setting in space and material frame of the temple, is embodied in architectonic forms. The light makes a mechanism of materialization of sacral appearance moveable in the architectural form („Easter light" is a window in the apse; "light from a height" is a dome on the light drum etc.). Architectural forms and temple elements, related to the light, due to certain principles of the organization, leaning on prototypes in accordance with theological and divine service requirements, are put in order in the structural architectonic model of the church building.

\section{Conclusion}

During the whole period of development of the traditional church architecture in Ukraine architectonically spatial organization of the light environment of the orthodox temple responds to theological requirements:

- priority of sacral and theological functions above aesthetical and utilitarian ones in the model of the light environment forming of the church;

- topside illumination prevailing of the temple; the hierarchy of the natural and artificial light according to the symbolic hierarchy of spaces in the basic volume of the sacred object; - semantic accordance of sacral light environment and its spatial form-creating elements. The light environment of the church with categories of a symbol and archetype is necessary to be considered as a method of tradition transference in the Orthodox Church, as an integral criterion of its architectonically spatial organization. The architecture of the orthodox temple is the architecture of the light.

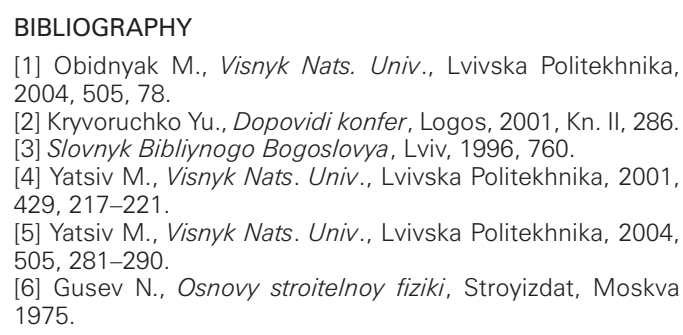

